\title{
SOME SOCIAL AND PSYCHOLOGICAL PROBLEMS OF AGEING
}

$\mathrm{T}$ THE programme of the British Association meeting last year in Belfast included a session by Section J (Psychology) on the problems of ageing. Mrs. M. Gilmore was in the chair. In the opening paper, which was a review of the problems of ageing in relation to medical science, read by Dr. G. F. Adams, physician to the Geriatric Department of the City Hospital, Belfast, the reasons were considered why old age should present problems in modern times any more than in the past. There has been $\mathbf{a}$ progressive increase, both absolute and relative, in the proportion of old people in the population, this increase being the result of the decline in infant and young adult mortality produced by the medical and social advances that have been made possible by the application of the scientific method during the past century. As a result of this, more old people must be supported by a diminished proportion of wage earners. There is a corresponding increase in the numbers of elderly invalids to be cared for, who are suffering from the degenerative diseases of old age which medical treatment may ameliorate, but not cure. Meanwhile, the expense of medical treatment, especially hospital treatment, has risen enormously and continues to rise, and it has been suggested that the community is faced with a gloomy prospect of unlimited 'medicated survival' to be met by diminishing resources. Dr. Adams disagreed with this view. Pointing out that medicine has long evaded its responsibilities to the clinical and social medicine of old age, being preoccupied in other fields of research, he outlined the new approach being made to the medical care of the elderly through the clinical work of hospital geriatric departments and the influence of social medicine in surveys of the problems of ageing. Much success has already been achieved in the prevention of unnecessary invalidism among the elderly sick, and many elderly patients hitherto regarded as 'chronic invalids' have been restored to activity, reducing the burden of nursing and domestic care otherwise necessary for them. Dr. Adams concluded that estimates of future needs for the elderly sick should be based on the results of such work rather than on limits set by the out-dated system of social and medical care of the past.

The second paper was read by Miss S. R. Burstein, of the Wellcome Historical Medical Museum, who urged that the problems of many old people are essentially mental rather than matters of physical infirmity or disease. The problems of adolescence have been the subject of a great deal of careful psychological and social research; there is a need for similar research upon the emotional problems concerned with the transition from middle to old age and especially upon the ways in which the years of old age can be used. It should be recognized that old age is not something which comes suddenlyageing is continuous from birth-and that it is fundamentally wrong to segregate old people as 'problem cases' away from the functioning life of the community.

Miss Burstein stressed that one of the difficulties for those doing research upon problems of old age is that they are usually younger, and that it is thus difficult for them to understand fully the outlook of the people with whom their research is concerned. She urged that discussion with old people individually or in small groups, if done with patience and respect, yields far more insight into their attitudes and needs than can methods such as questionnaire studies which are more immediately convenient to the research worker.

The traditional pattern in which the whole family, old and young, lived together under one roof has largely broken down, with the result that many old people are extremely lonely. A return to the traditional pattern is clearly impossible, and, even if it were, it might involve satisfying the needs of old people at an undue cost in terms of freedom and privacy for those younger. Intermediate solutions where, for example, old people live alone but close to younger relatives often work well. The point needs to be stressed, said Miss Burstein, that old people themselves must carry a large share of the responsibility for making such arrangements successful. Although they are often glad of the opportunity of leisure afforded by retirement, many of them are capable of useful work, and this applies not only to work at a job but also to help in the family as a functioning group.

Mrs. A. V. Hill, a member of the Advisory Council of the National Corporation for the Care of Old People, read the third paper, which was an account of some emotional changes observed in advanced old age-mainly between eighty and a hundred years. Although these emotional changes may accompany physical changes, the emotional needs of old people cannot be met by physical care alone. Little study has been made of old people's needs, and physical care without attention to emotional needs often constitutes actual cruelty. While certain main lines of emotional change can be observed, it should be emphasized that, on one hand, striking exceptions occur among very old people and that, on the other, changes can take place before any great old age in terms of years alone has been attained.

The behaviour of very old people can often be explained in terms of fear of death, or of illness or of change of environment. The will to live is as strong as ever, and fear of illness or accident may dominate the life of an old person. At the same time they may unconsciously feign illness in order to gain attention. Movement from one dwelling to another frequently produces a 'transference shock' with signs of mental and physical deterioration which can sometimes result in death. Usually, however, old people settle down in the new dwelling, although they may take some weeks to do so. This has been frequently noticed among new residents in old people's homes, and, when it seems likely to occur, the old people are persuaded not to cut adrift completely from their old haunts until they have come to know the new. Among other emotional attitudes, affection, friendship and concern for the opinions of others suffer a marked reduction. In the extreme, apathy and general indifference may appear, especially after long periods in bed. Interest 
in what immediately concerns oneself may increase : thus small treasures are hoarded, and interest in food may grow. At the same time, the gift of being able to "enjoy other people" often continues to the ond of a very long life.

Mrs. Hill urged that, broadly speaking, bed is bad for old people unless absolutely necessary on account of severe illness or weakness. Where possible, old people should be provided with small convenient dwellings where they can live alone. The independence and the effort involved in living alone can, as an example in one housing trust has shown, help old people to remain young for their age. Old people's clubs can help to relieve any loneliness which may be involved, and so also can part-time employment. An important experiment in the employment of people between seventy and eighty years of age for two hours daily is being made in Finsbury.

It is to be emphasized that people do not "suffer from old age" : they suffer from illness, unhappiness and loneliness, but not from old age as such. There seems to be an increasing tendency to resist and resent old age. Those old people who accept and understand its inevitability are emotionally in a much stronger position than others.

Dr. John A. Oliver, principal officer in the Ministry of Health and Local Government, Northern Ireland, read an address entitled "Thinking About Old Age", in which he gave an account of present-day social problems of the elderly, with some reflexions on social thought and social policy. He outlined the main features of the social problems of old age to-daymore people surviving into old age in a community distressed by $a$ housing shortage and a dearth of domestic help; and a weakening sense of family responsibility towards their elderly relatives on the part of parents anxious to give their children the best possible chance in difficult circumstances. This decline in family responsibility is encouraged, perhaps, by the lack of any legal obligation to provide for elderly relatives and by the increasing State provision being made for them. Dr. Oliver considered that the progress in social work and social legislation made in the last ten years has been largely pragmatic and has been "achieved without any real preparation in fundamental thinking". The practical workers beset by immediate problems have tackled them empirically as they arose, and our new social legislation, as it applies to the problems of ageing, has been launched in a philosophical vacuum. A philosophy of the social work, the social policy and the social services which we are operating must be evolved from experience and thought. Both legal and moral duties are involved in family responsibility for the aged, and we must recognize the fact that the State cannot be committed to an unlimited liability for the care of old people. Moreover, the hopes and desires of the old people themselves must be considered; and, since home is the normal place for most of them to live and end their days in, social services designed to make it easier to look after elderly relatives at home should be augmented and their potential contribution to industry encouraged by suitable work under suitable conditions. Is progress henceforward to depend on individual enterprise, asked Dr. Oliver"the effort of the old person, the effort of the relatives and the neighbours or on community services devised by the State"? He said that he believes that this choice between individualism and collectivism is the central philosophical problem in the so-called Welfare State. In conclusion, he suggested that the British
Association might establish a new section devoted to social science, or social philosophy, so that "British science may demonstrate its concern for social wellbeing and spiritual values".

Mr. A. 'T. Welford, director of the Nuffield Research Unit into Problems of Ageing, spoke of changes of human performance with age which affect capacity for industrial work. He stressed that many such changes associated with old age begin early in middle age, so that problems of employment for older people are not concerned only with those over the normal retiring-age. At some jobs ability seems to be well maintained into old age, and for almost all jobs a few older people can be found who are able to put up a performance comparable with that of a young man. At other jobs difficulties of maintaining adequate performance appear as early as the late forties. Difficulties of taking up a new job may appear earlier still.

The main difficulties for older people appear to be of three types, the first being where the form or the pace of the action involved is rigidly determined so that any slowness leads to an error of omission which cannot be afterwards redeemed. When the task is more flexible and the speed under the operator's control, an older person is often capable of compensating for slowness by increased care and accuracy. As a result of these compensatory tendencies, difficulties for people in later middle age in industrial work may go undetected-people maintain performance under an increasing strain until a suitable opportunity occurs to move away. Such moves are sometimes made following an illness which would not in itself warrant a change of job. Detailed examination of performance shows that often, contrary to popular opinion, slowness even in a manipulative task is due not to any limit set by the sense organs or by the effectors, but by the central brain processes which integrate and interpret information and form action.

The second type of difficulty occurs where the task is in some way complicated or confusing. So long as the relation between signals and the action required in response to them is simple and straightforward, performance by older people differs relatively little from that of younger. When, however, the relation is indirect or where several pieces of information have to be put together before action is taken, many older people are at a severe disadvantage.

The third type of difficulty is that of learning new tasks. This is, of course, generally recognized. The nature of the difficulty is not, however, clear. To some extent it is due to the application to the new task of previous habits which are not appropriate. In some cases, however, it appears to be due to inability to modify an erroneous method built up during early stages of practice.

In studying changes of performance with age, concluded Mr. Welford, it is important that we should not be led astray either by generalizations or by particular exceptional individuals. The ability of older people to do a job will depend both on the detailed demands of the job and upon the particular abilities which each individual can bring to it. Rigid general policies about retirement cannot therefore be justified on grounds of ability. The appropriate retirement-age will differ for the majority from one job to another, and from one individual to another at any job.

G. F. Adams

A. T. WELFORD 